tubes as narrow as possible consistent with convenience; and I am quite unable to imagine how anyone could be led to think that 1 intended to use such tubes in which to collect blood in practice. Further, I actually gave two methods by which $I$ find a very satisfactory yield of serum can be obtained without the possibility of contamination, even in the cold. By the method which Major Hine describes (which is, as he states, perfectly satisfactory for rabbit's blood), as a rule, only about two-thirds of the full theoretical yield can be obtained from human blood, and often much less. The "full theoretical yield," it seems necessary to point out, is for man almost exactly 50 per cent., and greater yields than this indicate anæmia.

I was already familiar with the method described by $\mathrm{Mr}$. T. H, C. Benians, and have found it very satisfactory when only small amounts of blood are being used. The only objection is that the large surface exposed facilitates evaporation and consequent concentration of the serum. The explanation of the method is simple : the retraction of the clot is great, because the latter is spread out into a thin layer, and is, further, fully assisted by gravily, since the serum drains away as soon as it is squeezed out. In my angled tubes (which I devised to deal with larger quantities of blood) I get the latter action, but not the former.

Dec. 21st, 1917 I am, Sir, yours faithfully, W. D"Estw EMgry.

\section{THE ADMINISTRATION OF BROMIDE.} To the Editor of THE LANCET.

SIR, - Everyone shculd be much indebted, in my opinion, to Dr. Maurice Craig for his very valuable letter in your issue of Dec. 29th, 1917, concerning the administration of bromides. Those who are not habitually and judgmatically using this drug have had arilled into them a certain series of trite phrases concerning the depressing and awful effects to such a degree that they fear to use it. Experience tells us that the susceptibility to bromide varies very greatly in different individuals, and that the dosage must be personal and decided by the method of trial and failure. Most people also forget (as is shown by Cushny) not only that the depression caused by the potassium and sodium action is apt to be confused with that of the bromide ion, but also that the result achieved by the exhibition of strychnine is better achieved by diminishing the dose of bromide after having first established the norm of personal susceptibility, for strychnine is a nerve irritant rather than a nerve stimulant.

More particularly would I like to emphasise the importance of small doses continued over long periods in cases of neurasthenia and persons of neurotic type. I have still under observation a case which exemplifies its great value in the person of a gentleman whom $I$ saw in consultation seven years ago whose work was largely brain work which, owing to his neurasthenic condition, only became possible to him by the steady maintenance of his bromide content produced by the administration of 15 grains daily, continued during the whole period. If the administration were discontinued, in a short time symptoms of irritability, \&c., returned, and work requiring any mental concentration became impossible. Far from any depressing effects being observed the converse is true, and this patient rightly regards his daily dose as the one thing that makes life possible to him. This, however, is only one of many cases of the same type which quite clearly confirm Dr. Craig's contention that patients more frequently suffer from the want of bromide than the use of it.

I am, Sir, yours faithfully,

JAMES R. WHITWELI.

St. Andry's Hospital, Melton, Suffolk, Jan. 1st, 1918.

\section{ETHER CLONUS}

\section{To the Editor of THE LANCET.}

SIR,-In answer to Dr. W. D. Anderson's query about ether clonus, speaking from an experience of over 3000 anæsthetics given by me since June, 1915, in this war bospital, I have found it of fairly frequent occurrence, though $I$ have made no note of when it occurred. I think it was more frequent among the old soldiers of the early convors that came here than recently among the soldiers of the new Army, but perhaps I have improved in my methods of giving ether. But in ordinary hospital and civil prac. tice I do not recollect ever to have been troubled with this complication, even when giving ether by the fully open method.

I have not, as far as I can recollect, noticed it in any cases where I have given ether by the semi-open method; in which method by either placing a folded towel round the mask, leaving a small opening for dropping. or using Ferguson's double-chamber mavk, as $I$ do now almost exclusively, the vapour becomes slightly warmed by the patient's breath. I only recently acquired a Shipway's warm ether apparatus, and I have used it very little as yet-only on about 20 occasions-so that I can hard'y say whether it prevents clonus, but I think it would almost certainly tend to do so. Curiously enough, this morning I encountered a man who gave slight manifestations of clonus during induction with C.E. mixture. He was a rather congested man, with a mitral bruit, but good compensation. Beyond that, and the fact that he required a larger dose of $C . E$. than the average of the men, he gave me no trouble during a 26-minutes administration (of C.F.).

With reference to your annotation, speaking of the advantages of chloroform as a stand-by for the general practitioner giving an occasional anæsthetic, I would personally give the preference to $\mathrm{C} . \mathrm{E}$. mixture (chloroform two, ether three parts by measure) as being far safer and almost equally portable. I fully agree with your remarks as to Junker's apparatus, and where $I$ am obliged to give pure chloroform I never use any other met hod. I have found $\mathrm{Mr}$. Tom Bird's celluloid cone very useful with the Junker I am, Sir, yours faithfully,

\section{A. DE WINTER BAKER,}

The Horton (County of London)

War Hospital, Epsom, Dec. 22nd, 1917 Senior Anæsthetist.

\section{SPHAGNUM MOSS.}

\section{To the Editor of THE LANCWT.}

SIR,-Will you permit me to draw the attention of surgeons who are using sphagnum moss in military hospitals to the compressed form of moss dressings. ${ }^{1}$ Owing to their small bulk there is saving of cubic space in transport, also economy in use of packing materials. They are very carefully sublimated and otherwise prepared by workers who have had some years' experience. Before use the compressed dressing has to be expanded by soaking in lotion, but this is a very simple proceeding, and full directions are sent along with the dressings. At present the workshops for preparing these dressings are capable of turning out considerably more than they are at present asked to do, and as this form of dressing may not be so well known as the other I wish to draw attention to it. Samples of compressed dressings which are made in standard sizes will be forwarded by application to the D.G.V.O.

I am, Sir, yours faithfully,

Charles W. Cathearis,

Lieutenant-Colonel, R.A.M.C.TT.

3. Tipperlinn-road. Edínburgb, Dec. 27th, 1917.

1 THE LANCET, 1916, i., 820.

THE LANCET, VOL. II., 1917 : THE INDEX.

THE Index and Title-page to the volume of THE LANCET completed with the issue of Dec. 29th will be ready shortly. Owing to the increasing shortage in the paper-supply, the Index will not be issued with all copies of THE LANCET, as was the custom prior to the War. Subscribers who bind up their numbers are requested to send a post-card to the Manager, ThE LANCET Office, 423, Strand, London, W.C. 2, when a copy of the Index and Titje-page will be supplied free of charge. 